\title{
Research of the Mechanism of Low Frequency Oscillation Based on Dynamic Damping Effect
}

\author{
Wenying Liu*, Rundong Ge ${ }^{\dagger}$, Dandan Zhu*, Weizhou Wang**, Wei Zheng** \\ and Fuchao Liu**
}

\begin{abstract}
For now, there are some low frequency oscillations in the power system which feature low frequency oscillation with positive damping and cannot be explained by traditional low frequency oscillation mechanisms. Concerning this issue, the dynamic damping effect is put forward on the basis of the power-angle curve and the study of damping torque in this article. That is, in the process of oscillation, damping will dynamically change and will be less than that of the stable operating point especially when the angle of the stable operating point and the oscillation amplitude are large. In a situation with weak damping, the damping may turn negative when the oscillation amplitude increases to a certain extent, which may result in an amplitude-increasing oscillation. Finally, the simulation of the two-machine two-area system verifies the arguments in this paper which may provide new ideas for the analysis and control of some unclear low frequency phenomena.
\end{abstract}

Keywords: Low frequency oscillation mechanism, Damping torque, The dynamic damping effect

\section{Introduction}

Low frequency oscillations [1-3] have been reported in power systems all over world since 1960s. From then on, great attentions have been paid to the oscillations for the secure of power systems. Among these researches, the mechanism of the oscillations which is fundamental is no doubt a significant part.

The traditional oscillation mechanisms mainly include the resonance mechanism and the negative damping mechanism, and the latter one has been perfected now. While, as a matter of fact, the above traditional theories are far from explaining all the observed oscillations. On October 29th, 2005, power fluctuations were detected in large range of Central China Power Grid, which turned to be negative damping oscillation judged from the first 9 cycles. While post hoc analysis had shown that the damping of grid then was weak but positive. On May 13th, 2005 , the power oscillation occurred on the connection lines including Yunnan-Tianshengqiao, Tianshengqiao-Guangdong, Guangdong-Hongkong and Guizhou-Guangdong in China Southern Power Grid. The later researches showed that large amounts of PSS were out of service and that the damping of grid was weak during the oscillation at that moment. The underlying cause for the oscillation is still unknown today. These two events both feature an amplitude-increasing low frequency oscillation with positive

$\dagger$ Corresponding Author: Electrical and Electronic Engineering Institute, North China Electric Power University, China. (gerundong 19870505@126.com)

* Electrical and Electronic Engineering Institute, North China Electric Power University, China.

** Gansu Electric Power Research Institute, China.

Received: November 4, 2014; Accepted: May 4, 2015 damping.

Based on this, the effectiveness and defect of traditional low frequency oscillation mechanisms are demonstrated firstly in this paper. Aware of the crucial impact of nonlinearity on the low frequency oscillation, the current nonlinear theories used in oscillations are also summarized. To interpret the phenomenon of the amplitude-increasing oscillation with positive damping, the actual power-angle swing trajectory considering the damping power is studied based on the damping torque characteristic. Then the dynamic damping effect is introduced which is then employed to reveal the mechanism of these unexplained low-frequency oscillations. In the end, the simulation of the two-machine two-area system verifies the arguments in the paper, which may provide new approaches for the analysis and control of some unclear low-frequency oscillation phenomena.

\section{The Traditional Low-frequency Oscillation Mechanism and its Fitness for These Oscillations}

For now, the traditional low frequency oscillation mechanisms mainly include the resonance mechanism and the negative damping mechanism.

\subsection{The resonance mechanism and its fitness for these oscillations}

The resonance mechanism $[4,5]$ points out that the disturbance whose frequency is close to the natural frequency of the power system may cause forced oscillations. The forced oscillation is usually characterized 
with a quick vibration and an immediate attenuation after the disturbance source is lost. While both the oscillations observed in Central China Power Grid and China Southern Power Grid experience a relative long vibration and were damped out by changing the operation mode. As these features differ greatly from those of a forced resonance oscillation, the resonance mechanism cannot explain the two oscillations properly.

\subsection{The negative damping mechanism and its fitness for these oscillations}

Negative damping mechanism [6-8] is currently the most mature theory among the low-frequency oscillation mechanisms. It believes that the oscillation is caused by lack of system damping. If the damping is positive, the system operates steadily. If the damping is negative, any slight disturbance will be enlarged gradually and eventually break down the system. There are mainly two methods we can employ to analyze oscillations based on the negative damping mechanism. One is the eigenvalue method [9, $10]$, which obtains the eigenvalue from the system state matrix through the linearization of the non-linear differential equations so as to determine the stability of the system. The other one is the extraction method $[11,12]$ based on the disturbance trajectory. It obtains the oscillation frequency, damping ration and some other information from the time series data by analyzing signals.

However, the above methods both have their inherent defects. The power system is a strong nonlinear system. The eigenvalue method uses the linearized model which determines that the analysis ignores the dynamic change after the system reaches a nonlinear region. Thus the results are the damping coefficients of the equilibrium point. In addition, the eigenvalue method may miss some key oscillation modes because of the phenomenon of losing roots when dealing with a large system. As for the pattern extraction method, its essence is the simple analysis of signal which fails to expose the nature of the cause of oscillation.

As a matter of fact, the two above low frequency oscillations in 2005 are amplitude-increasing oscillations with positive damping which the traditional negative damping mechanism cannot explain on account of the defects in these methods.

\section{Effects of Nonlinearity on Low Frequency Oscillation}

Because the traditional low frequency oscillation mechanism has difficulties in analyzing some oscillation phenomena, researches have been carried out into the effects of nonlinearity on low frequency oscillations in attempt to interpret the unclear oscillations from a nonlinear angle. The literatrue $[8,13]$ point out that the low-frequency oscillation with large amplitude considering nonlinearity belongs to large-disturbance rotor angle stability but not the small signal stability. Then the effects of the nonlinearity on the dynamic characteristic of the system cannot be ignored. Hopf bifurcation is adopted in literatrue [14] to study the nonlinear oscillations of the system. However, the bifurcation theory which is still at the exploratory stage cannot be applied to the large-scale system. Quadratic term is used to study the interactive effect between deferent modes based on the theory of normal forms method $[15,16]$ and the modal series method $[17,18]$. However, these methods are complicated, and they can only reflect the nonlinear characteristics of equilibrium point and points nearby, but cannot count greater-range nonlinear factors in.

Actually, when the damping of the system is strong and the amplitude of oscillation is not large, the overall damping observed is very close to that of the original equilibrium because the impact of nonlinear factors is not big. However when the amplitude of oscillation is large, the operation state has gone far away from the original equilibrium in the swing process. With the dynamic change of power angle, the damping characteristic of the actual system has undergone a great change. Especially when the damping of the system is weak, the overall damping observed in the process of large-amplitude oscillation will decrease with respect to that of the original equilibrium. Based on the power-angle swing curve, explanations to these unclear low-frequency oscillations will be given in this paper from the vantage of dynamic damping characteristics in the swing.

\section{Analysis of the Dynamic Damping Effect in Power System}

The damping characteristic is closely related to the damping torque. And the change of damping torque will affect the damping power, which may draw the powerangle swing trajectory away from the original swing curve in a dynamic process. The dynamic damping effect is put forward in this section on the basis of power angle swing trajectory analysis.

\subsection{Generator damping torque characteristics}

As the traditional negative damping mechanism is established on the time-invariant linear system model, the damping torque $D$ is assumed to be constant there. While, in fact, $D$ is not a constant. $D$ can be obtained through formula (1).

$$
D=D_{1}+M_{D}
$$

where, $D_{1}$ is the natural damping torque of the generator, which includes the damping torque caused by wind 
resistance and mechanical friction; $M_{D}$ is the damping torque caused by the change of flux linkage.

$D_{1}$ can be assumed to be constant, so the change of $D$ is mainly caused by $M_{D}$. According to the Heffron-Philips model [19] of the single-machine infinite-bus system, when the generator is equipped with fast excitation system, $M_{D}$ can be expressed as formula (2).

$$
M_{D}=\frac{K_{2} K_{5} K_{A} T_{d 0}^{\prime}}{K_{A}^{2} \mathrm{~K}_{6}^{2}+\omega_{d}^{2} T_{d 0}^{\prime 2}}
$$

In this formula, $T_{d 0}^{\prime}$ is the direct-axis transient opencircuit time constant, $K_{A}$ is the magnification of excitation system, $\omega_{d}$ is the angular frequency of oscillation. For a certain system and oscillation mode, the variables mentioned above are all constants. Among the formula (2), the expressions of $K_{2}, K_{5}, K_{6}$ are as following:

$$
\begin{gathered}
K_{2}=i_{q}\left[1+\frac{\left(x_{1}+x_{q}\right)\left(x_{q}-x_{d}^{\prime}\right)}{A}\right] \\
K_{5}=\frac{u_{t d}}{U_{t}} x_{q}\left[\frac{\left(x_{1}+x_{d}^{\prime}\right) U \cos \delta}{A}\right]- \\
\frac{u_{t q}}{U_{t}} x_{d}^{\prime}\left[\frac{\left(x_{1}+x_{q}\right) U \sin \delta}{A}\right] \\
K_{6}=\frac{u_{t q}}{U_{t}}\left[1-\frac{x_{d}^{\prime}\left(x_{1}+x_{q}\right)}{A}\right] \\
A=\left(x_{1}+x_{d}^{\prime}\right)\left(x_{q}+x_{1}\right)
\end{gathered}
$$

In these formulas, $x_{q}$ is the quadrature-axis synchronous reactance, $x_{d}^{\prime}$ is the direct-axis transient reactance, $x_{1}$ is the reactance from the generator to the infinite bus, $U_{t}$ is the voltage amplitude of generator terminal, $u_{t d}, u_{t q}$ represent the direct and quadrature axis components of generator terminal voltage, $i_{q}$ is the quadrature axis component of generator current, $\delta$ is the relative advance angular of the transient potential $E^{\prime}$ to the voltage $U$ of the infinite bus.

Assume that $K=K_{2} K_{5}, K^{\prime}=K_{6}^{2}$, then,

$$
M_{D}=\frac{K \times K_{A} T_{d 0}^{\prime}}{K^{\prime} \times K_{A}^{2}+\omega_{d}^{2} T_{d 0}^{\prime 2}}
$$

$i_{q}, u_{t d}, u_{t q}, \sin \delta$ and $\cos \delta$ are functions of power angle $\delta$, whose values will change as the power angle fluctuates. Then $K$ and $K^{\prime}$ will also undulate, which will change the value of $D$ and $M_{D}$.

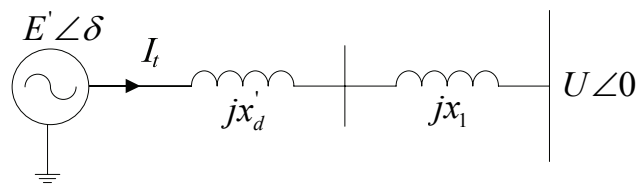

Fig. 1. Single-machine infinite bus system

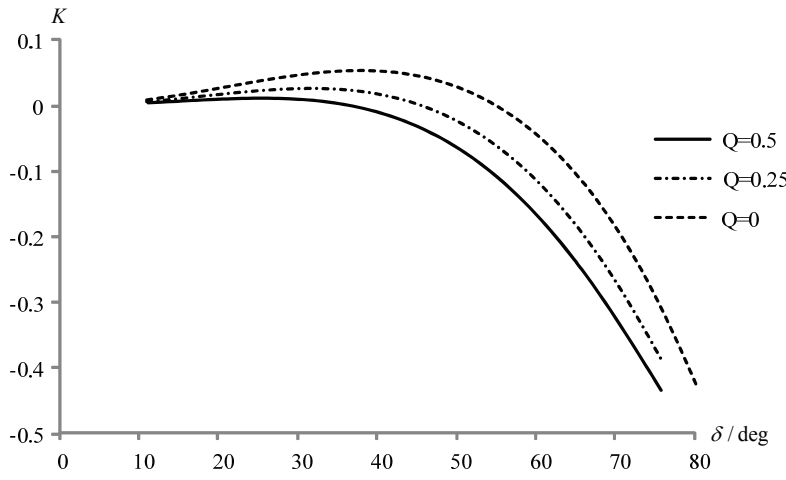

Fig. 2. The curves of $K$ with the changing angle under different reactive power levels

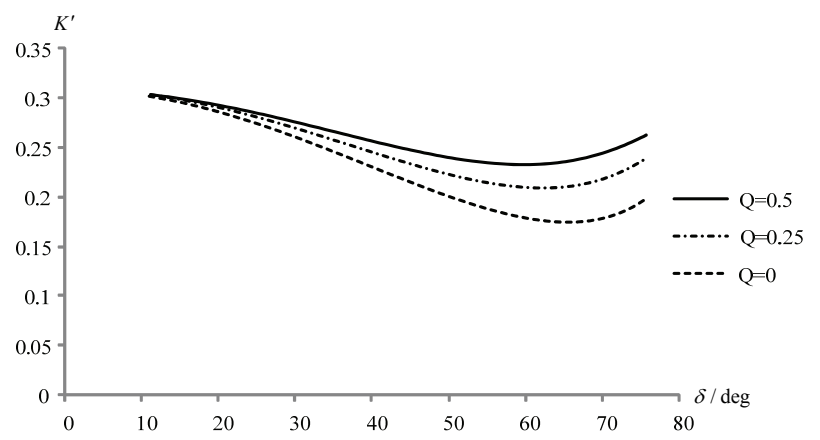

Fig. 3. The curves of $K^{\prime}$ with the changing angle under different reactive power levels

In order to illustrate the damping torque characteristic of generator in a general system, a single-machine infinitebus system, as shown in Fig. 1, is taken as an example in this paper. The change curves of $K$ and $K^{\prime}$ in the system with respect to power angle are obtained by calculation.

The power reference value is set as 100MVA, the parameters (p.u.) are as following: $x_{1}=0.4, x_{d}=1.6, x_{q}=1.55$, $x_{d}^{\prime}=0.32$. Keep the reactive power $Q$ transmitted from the generator to infinite bus constant and increase the output active power, the power angle $\delta$ will increase. The curves of $K$ and $K^{\prime}$ with the changing angle under different reactive power levels are shown in Fig. 2 and Fig. 3.

As can be seen from Fig. 2 and Fig. 3, with power angle increasing, $K$ increases first and then decreases, while $K^{\prime}$ decreases first and then increase. It has to be pointed out that when power angle increases after having reached a certain point, $K$ will turn negative and experience a rapid decrease. $K^{\prime}$ remains positive however the power angle changes, and the variation is not big. According to formula (1) and formula (7), $D$ and $M_{D}$ increase first and then decrease rapidly with power angle increasing. And when $K$ is negative, $M_{D}$ is also negative. When the power angle is great enough, where $M_{D}$ offsets the inherent damping torque $D_{1}, D$ will turn negative.

\subsection{Damping power}

In the process of oscillation, damping power $P_{D}$ can be 
obtained as formula (8).

$$
P_{D}=D(\omega-1)
$$

As formula (8) shows, in the power angle swing process, with the damping torque $D$ and rotor speed $\omega$ fluctuating, damping power will thus change, which will definitely affect the swing trajectory of power angle.

\subsection{The actual power angle swing trajectory con- sidering damping power}

The mechanical power output of the prime mover is set to $P_{m 0}, P_{E}$ represents the power-angle curve of generator, $\delta_{s}$ is the power angle of the stable operation point on the curve $P_{E}$. Assume that the power angle swings in the range of $\left[\delta_{1}, \delta_{2}\right]$ in a circle.

Ignoring the damping power, the power angle of generator will oscillate along the curve $P_{E}$ during an oscillation.

Considering the influence of dynamic damping power, the damping power needs to be superimposed over the original power-angle curve $P_{E}$. Then positive damping power will elevate the power-angle curve, and negative damping power will reduce the curve. The extent of deviation from the original power-angle curve is proportional to the damping power.

For a system with weak damping, the power angle of the stable operation point $\delta_{s}$ is relatively large. According to analysis in section 4.1, damping torque then will undergo a rapid decrease with the power angle increasing. In a largeamplitude swing, the damping torque may turn negative, which will affect the damping power. Taking the process of the power angle turning from $\delta_{1}$ to $\delta_{2}$ as an example, analysis will be presented next.

$\delta_{1}$ and $\delta_{2}$ are two extremes of the power angle, where $\mathrm{d} \delta / \mathrm{d} t=0$. So in the per unit system, $\omega=1$ and the corresponding damping power is 0 at the two points. As a result, the operation point is on the power angle curve $P_{E}$.

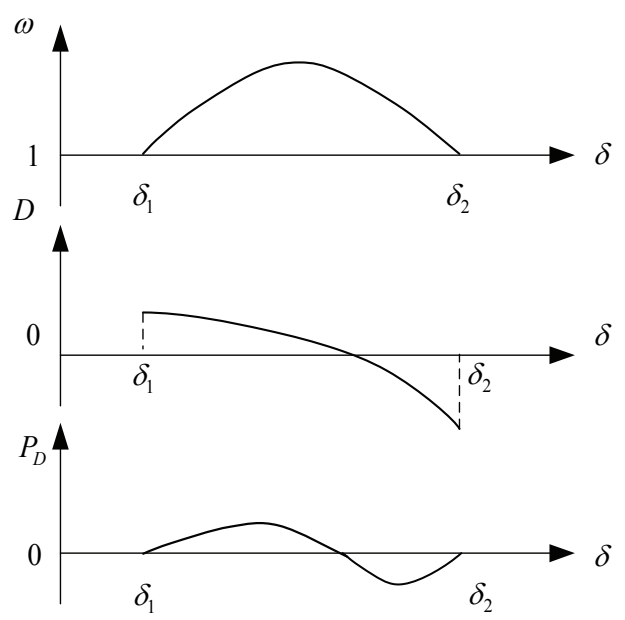

Fig. 4. The traces of $\omega, D, P_{D}$ with the changing angle
In the process of the power angle increasing from $\delta_{1}$ to $\delta_{2}$, if the superimposed power angle curve is under $P_{m 0}$, then the rotor accelerates; if the curve is above $P_{m 0}$, then the rotor decelerates. As a result, $\omega$ increases first and then decreases, but remains greater than 1 through the process. The damping torque decreases all the time, turning negative from positive. According to formula (8), when the power angle is $\delta_{1}$, the corresponding damping power is 0 . And with the power angle getting larger to $\delta_{2}$, the damping power will increase first and then decrease to 0 , then the value of damping power turns negative and its absolute value increases first and then decreeses to 0 . The traces of rotor speed $\omega$, damping torque $D$, damping power $P_{D}$ with the changing angle are shown in Fig. 4.

The mechanism of the power angle movement from $\delta_{2}$ to $\delta_{1}$ is the same, though the process is reversed. The actual swing trajectory of power angle in the circle considering the dynamic damping power should be $1 \rightarrow 2 \rightarrow 5 \rightarrow 6 \rightarrow$ $3 \rightarrow 7 \rightarrow 5 \rightarrow 4 \rightarrow 1$, as shown in Fig. 5 .

As shown in Fig. 5, point 1 and 3 are on the curve $P_{E}$. The power angle of point 1 is $\delta_{1}$, and that of point 3 is $\delta_{2}$. Point 2 and 4 are intersection points of the superimposed curve and the horizontal line of $P_{m 0}$. Point 5, where the damping torque is 0 , is on the curve $P_{E}$. Point 6 , which is between point 5 and 3 , is on the curve deviating downward from $P_{E}$. Point 7, which is between point 3 and 5, is on the curve deviating upward from $P_{E}$.

The changes of rotor speed $\omega$, damping torque $D$ and damping power $P_{D}$ in one oscillating cycle are shown is Fig. 6.

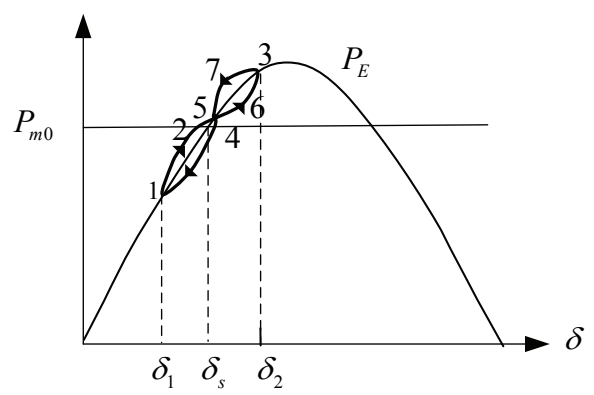

Fig. 5. The trace of the power-angle considering the dynamic damping

\begin{tabular}{|c|c|c|c|c|c|}
\hline $\begin{array}{c}D>0, \quad D \downarrow \\
\omega>0,|\omega| \uparrow \\
P_{D}>0\end{array}$ & & $\begin{array}{c}D>0, \quad D \downarrow \\
\omega>0,|\omega| \downarrow \\
P_{D}>0\end{array}$ & & $\begin{array}{c}D<0,|D| \uparrow \\
\omega>0,|\omega| \downarrow \\
P_{D}<0\end{array}$ & $\begin{array}{c}D<0,|D| \uparrow \\
\omega>0,|\omega| \downarrow \\
P_{D}<0\end{array}$ \\
\hline 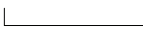 & $\perp$ & & 1 & & $\perp$ \\
\hline$\longrightarrow$ & 2 & $\longrightarrow$ & 5 & $\longrightarrow$ & $\longrightarrow$ \\
\hline$D<0,|D| \downarrow$ & & $D<0,|D| \downarrow$ & & $D>0, \quad D \uparrow$ & $D>0, \quad D \uparrow$ \\
\hline$\omega<0,|\omega| \uparrow$ & & $\omega<0,|\omega| \uparrow$ & & $\omega<0,|\omega| \uparrow$ & $\omega<0,|\omega| \downarrow$ \\
\hline$P_{D}>0$ & & $P_{D}>0$ & & $P_{D}<0$ & $P_{D}<0$ \\
\hline $\mid$ & 1 & & & & $\perp$ \\
\hline$\longrightarrow$ & 7 & $\longrightarrow$ & & & $\longrightarrow$ \\
\hline
\end{tabular}

Fig. 6. The change of rotor speed and damping torque in one oscillating cycle 


\subsection{Analysis of the dynamic damping effect based on swing trajectory}

According to the analysis in the equal-area criterion [20], work done can be represented by the area surrounded by power curve. The work done by damping power in an oscillation circle is as formula (9).

$$
W=\int P_{D} d \delta=\int D \dot{\delta} d \delta=S_{21}-S_{22}
$$

where, $S_{21}$ is the area surrounded by curve $1,2,4,5 ; S_{22}$ is the area surrounded by curve $5,6,3,7$. Let the equivalent average damping torque in the circle be $\bar{D}$, then,

$$
W=\bar{D} \int \dot{\delta} d \delta
$$

According to formula (9), formula (10),

$$
\bar{D}=\frac{W}{\int \dot{\delta} d \delta}=\frac{S_{21}-S_{22}}{\int \dot{\delta} d \delta}
$$

If $S_{21}>S_{22}$, then $\bar{D}>0$ and the damping in the oscillation is positive. So the amplitude of oscillation will decay.

In a system with weak damping, if the power angle of the stable operation point is large, the damping torque will turn negative with the power angle increasing and will decrease rapidly. As a consequence, $S_{22}$ will increase with respect to $S_{21}$ as the oscillation amplitude increasing. And the average damping torque will be smaller than that of stable operation point during the swing. If the amplitude of the oscillation reaches a certain extent when $S_{21}<S_{22}$, then $\bar{D}<0$ and the damping will be negative as a whole.

Therefore, $\bar{D}$ changes with the amplitude of oscillation differing. Especially in a situation where the power angle of the stable operation point and the oscillation amplitude are large, the damping will be smaller than that of the stable equilibrium. This is the dynamic damping effect. Under the dynamic damping effect, in a system with weak damping, when the swing amplitude of the power angle is large enough, the average damping torque may turn negative.

\section{Research of Low Frequency Oscillation Mechanism Based on Dynamic Damping Effect}

Assume that there are $n$ swing circles in a certain period and the average damping torque in this period is $\overline{\bar{D}}$. Then,

$$
\overline{\bar{D}} \sum_{i=1}^{n} \int_{i}^{\bullet} \dot{\delta} d \delta=\sum_{i=1}^{n} \bar{D}_{i} \int_{i}^{\bullet} \dot{\delta} d \delta
$$

The subscript $i$ denotes the variables in the $i$ th circle, then,

$$
\overline{\bar{D}}=\frac{\sum_{i=1}^{n} \bar{D}_{i} \int_{i}^{\bullet} \dot{\delta} d \delta}{\sum_{i=1}^{n} \int_{i} \dot{\delta} d \delta}
$$

During the first swing circle, if the average damping torque is negative, i.e. $\bar{D}_{1}<0$, it will further increase the oscillation amplitude, which will cause the damping to drop further in the following oscillations. According to formula (13), $\bar{D}_{i}<0$ will result in $\overline{\bar{D}}<0$. So under some circumstances, the system still exhibits an overall negative damping during the power angle swing because of the dynamic damping effect, though the damping of stable equilibrium of the system is positive. Actually, the essential reason lies in that the damping deviates from the one of the stable operation state because of nonlinearity in the situation of large-amplitude power angle swing. The occasion tends to happen especially when the damping of the system is weak or extremely weak.

As a matter of fact, before the low frequency oscillations in 2005 mentioned, the damping of the power grid was weak. The original deviation of power angle mixed with the disturbances, change of operation mode, nonlinearity and some other factors made it possible for the amplitudeincreasing low frequency oscillations to happen, just because of the dynamic damping effect. So the dynamic damping effect can properly explain the two low frequency oscillations.

\section{Case study}

A two-area two-generator system is analyzed with PSASP(Power System Analysis Software Package) 6.28 developed by China Electric Power Research Institute in this section to verify the arguments proposed in this paper. The wiring diagram of the system is shown in Fig. 7, and the model and its parameters are presented in appendix.

Load at $L_{3} P_{L 3}=1840 \mathrm{MW}$, output of generator $G_{1} P_{1}=$ $1004 \mathrm{MW}$, output of generator $G_{2} P_{2}=870.17 \mathrm{MW}, Q_{2}=$ 203.81Mvar. The oscillation modes can be got with eigenvalue method. Specified information about the modes is shown in Table 1.

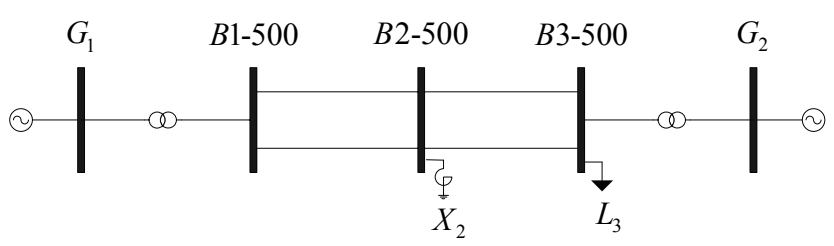

Fig. 7. The wiring diagram of two-area two-generator system 
Table 1. The low-frequency oscillation mode with weak damping in the two-machine two-area system

\begin{tabular}{c|c|c|c|c}
\hline $\begin{array}{c}\text { Mode } \\
\text { number }\end{array}$ & $\begin{array}{c}\text { Real part of } \\
\text { eigenvalue }\end{array}$ & $\begin{array}{c}\text { Imaginary part } \\
\text { of eigenvalue }\end{array}$ & $\begin{array}{c}\text { Frequency } \\
(\mathrm{Hz})\end{array}$ & $\begin{array}{c}\text { Damping } \\
\text { ratio (\%) }\end{array}$ \\
\hline 1 & -0.06418 & 5.59 & 0.89 & 1.15 \\
\hline
\end{tabular}

The oscillation mode is one inter-area Modes between $G_{1}$ and $G_{2}$. As the damping ratio of the listed oscillation mode is $1.15 \%$, this is a weak damping oscillation.

The damping characteristic during oscillations is observed through imposing a large disturbance to the system to offset a low-frequency oscillation. The disturbance created is a three-phase instantaneous short circuit fault on $B 1$ 500- $B 2-500$ I line, $2 \%$ away from $B 1-500$, at $1 \mathrm{sec}$ and the line trips at $1.1 \mathrm{sec}, 0.6 \mathrm{~s}$ later, this very line recloses successfully. Swing curve of the relative power-angle between $G_{1}$ and $G_{2}$ when three-phase instantaneous short circuit failure occurs is shown in Fig. 8 .

As can be seen from Fig. 8, the system experiences a slow amplitude-increasing low frequency oscillation after the fault is cleared. To eliminate the influence of the fault, the swing curve of $5 \mathrm{~s}-15 \mathrm{~s}$ is chosen as the prony analysis subject. The prony analysis result is shown is Table 2 .

As can be seen from Table 1 and 2, the difference of the actual damping ratio in the oscillation and that of the stable equilibrium is up to $1.33 \%$. A negative damping is observed. The essential difference between the results of eigenvalue analysis and prony analysis has verified the existence of the dynamic damping effect. Thus, when the system is in a situation with weak damping, immediate measures should be taken to raise the damping to avoid the low frequency oscillations.

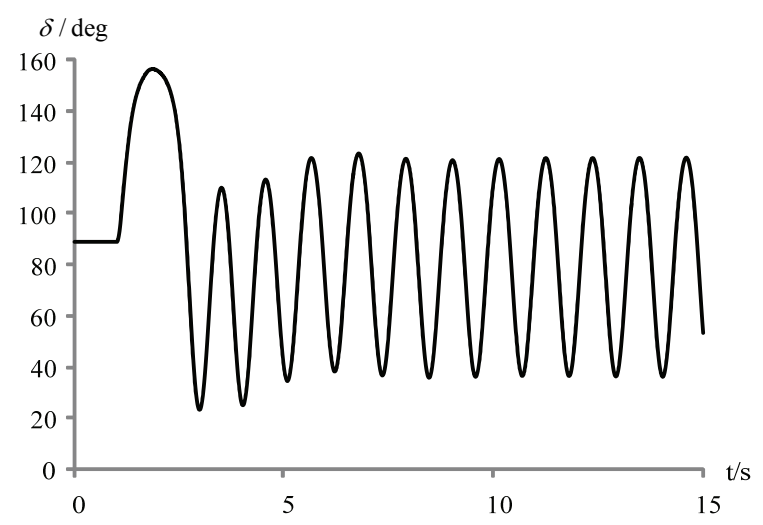

Fig. 8. Swing curve of the relative power-angle of $G_{1}$ and $G_{2}$ when three-phase instantaneous short circuit failure occurs

Table 2. Prony analysis results of the power-angle swing curve

\begin{tabular}{c|c|c|c|c}
\hline Time(s) & Amplitude & Decay & $\begin{array}{c}\text { Frequency } \\
(\mathrm{HZ})\end{array}$ & $\begin{array}{c}\text { Damping Ratio } \\
(\%)\end{array}$ \\
\hline $5-15$ & 17.23 & 0.10274 & 0.89 & -0.18 \\
\hline
\end{tabular}

\section{Conclusions}

1) The dynamic damping effect is proposed in this paper. The damping will undergo a dynamic change during an oscillation, especially in a situation when the power angle of the stable operation point and the oscillation amplitude are large, the damping will be smaller than that of the stable equilibrium.

2) Some unexplained low-frequency oscillations can be explained based on the dynamic damping effect. Under the dynamic effect, in a system with weak damping, when the swing amplitude of the power angle is large enough, the average damping torque may turn negative which is accompanied with amplitude-increasing oscillations, providing a new idea for the analysis and control of some unclear low frequency phenomena.

3) A two-area two-generator system is taken as an example. And the essential difference between the results of eigenvalue analysis and Prony analysis verified the existence of dynamic damping effect.

4) This paper doesn't include the research on the cause of the original deviation of power angle, which will be presented in the next paper. And some other lowfrequency oscillation phenomena whose mechanism remains unrevealed will be further analyzed in the future work.

\section{Acknowledgements}

This work is supported by the project "Research of The Impact Mechanism on Self-organized Critical State by Large-scale Cluster Grid-connected Wind Power and Identification" funded by National Science Foundation of China (51377053) and the project "The Comprehensive Security Warning and Control Technology Research with the System Development for Power Grid" funded by Major Project of State Grid Corporation of China (2011103004).

\section{References}

[1] Sehleif F. R., and White J. H., "Damping for the northwest-southwest tieline oscillations-An analog study," IEEE Transactions on Power Apparatus and Systems, vol. 85, no. 12, pp. 1239-1247, 1996.

[2] Western System Coordinating Council (WSCC). "Disturbance report for the power system outage that occurred on the Western Interconnection on August 10th, 1996 at 1548 Past, October 1996".

[3] Vournas C.D., Metsiou A., and Nomikos B.M., "Analysis of intra-area and interarea oscillations in south-eastern UCT interconnection," IEEE PES General Meeting(PES), Calgary, Canada, July, 2009.

[4] Xu Yanhui, and Zhang Jingbo, "The resonance mech- 
anism low frequency oscillations induced by nonlinear governor system," 2011 International conference on business management and electric information, Guangzhou, China, May, 2011.

[5] Xin Jianbo, Han Zhiyong, Wu Guoping, He Renmu, and $\mathrm{Xu}$ Yanhui, "Energy analysis of power system low frequency oscillation of resonance mechanism," Third International Conference on Electric Utility Deregulation and Restructuring and Power Technologies, Nanjing, China, April, 2008.

[6] Demello F. P., and Concordia C., "Concepts of synchronous machine stability as affected by excitation control," IEEE Transactions on Power Apparatus and Systems, vol. 88, no. 4, pp. 316-329, April, 1969.

[7] Banaei MR., and Hashemi A., "An Adaptive UPFC Based Stabilizer for Damping of Low Frequency Oscillation," Journal of Electrical Engineering \& Technology, vol. 5, no. 2, pp. 197-208, June 2010.

[8] KUNDUR P. Power system stability and control, McGraw-Hill, chapter.12, 1994.

[9] Kim Dong-Joon, and Moon Young-Hwan, "Application of the Implicit Restarted Arnoldi Method to the Small-Signal Stability of Power Systems," Journal of Electrical Engineering \& Technology, vol. 2, no. 4, pp. 428-433, December 2007.

[10] Dahal S., Mithulananthan N., and Saha T.K., "Assessment and Enhancement of Small Signal Stability of a Renewable-Energy-Based Electricity Distribution System," IEEE Transactions on sustainable energy, vol. 3, no. 3, pp. 407-415, July 2012.

[11] Choi JH, Shim KS, Nam HK, Lim YC, and Nam SR, "Parameter Estimation Method of Low-Frequency Oscillating Signals Using Discrete Fourier Transforms," Journal of Electrical Engineering \& Technology, vol. 7, no. 2, pp. 162-170, March 2012.

[12] Neto C.M.S., Costa F.B., Barreto R.L., Rocha T.O.A., Ribeiro R.L.A., "Wavelet-based method for detection of electrical and electromechanical oscillations in synchronous generators," 2013 Brazilian Power Electronics Conference, Gramado, Brazil, October 2013.

[13] IEEE/CIGRE Joint Task Force on Stability Terms and Definitions, "Definition and Classification of Power System Stability," IEEE Transactions on Power System, vol. 19, no. 3, pp. 1387-1401, August 2004.

[14] Ajjarapu V., and Lee B., "Bifurcation theory and its application to nonlinear dynamical phenomena in an electrical power system", IEEE Transactions on Power Systems, vol. 7, no. 1, pp. 424-431, February 1992.

[15] Sanchez-Gasca J. J., Vittal V., Gibbard M. J., Messina A. R., Vowles D. J., Liu S., and Annakkage U.D., "Inclusion of higher order terms for small-signal (modal) analysis: committee report-task force on assessing the need to include higher order terms for small-signal (modal) analysis," IEEE Transactions on
Power Systems, vol. 20, No. 4, pp. 1886-1904, November 2005.

[16] HIROYUKI A., TERUHISA K, and TOSHIO, I., "Nonlinear stability indexes of power swing oscillation using normal form analysis," IEEE Transactions on Power Systems, vol.21, no.2, pp.825-833, May 2006.

[17] Shanechi H.M., Pariz N., and Vaahedi E., "General nonlinear modal representation of large scale power systems," IEEE Transactions on Power Systems, vol. 18, no. 3, pp. 1103-1109, August 2003.

[18] Pariz N., Shanechi H.M., and Vaahedi E., "Explaining and validating stressed power systems behavior using modal series," IEEE Transactions on Power Systems, vol. 18, no. 2, pp. 778-785, May 2003.

[19] El-Sherbing M. K., and Mehta D. M.. "Dynamic System Stability: Part I - Investigation of the Effect of Different Loading and Excitation System," IEEE Trans On PAS, Vol. 92, No. 5, pp. 538-1546, SeptemberOctober 1973.

[20] J DUNCAN GLOVER, MULUKUTLA S. SARMA., THOMAS OVERBYE. Power system analysis and design, Thomson Learning, chapter.11 2008.

\section{Appendix A}

Appendix A1. The model and parameters of generator $G_{1}$

Rated Capacity: 1333MVA, Rated Voltage: 18KV.

Parameters of $G_{1}$ with rated capacity and voltage are as shown in Table A1.

Table A1. The parameter of generator $\mathrm{G}_{1}$

\begin{tabular}{l|c|l|c}
\hline \multicolumn{1}{c|}{ Variables } & $\begin{array}{c}\text { Value } \\
\text { pu or s) }\end{array}$ & \multicolumn{1}{|c}{ Variables } & $\begin{array}{c}\text { Value } \\
\text { pu or s })\end{array}$ \\
\hline $\begin{array}{l}\text { d-axis synchronous } \\
\text { reactance } x_{d}\end{array}$ & 2.16 & $\begin{array}{l}\text { rotor inertia time constant } \\
T_{j}\end{array}$ & 8 \\
\hline $\begin{array}{l}\text { d-axis transient } \\
\text { reactance } x_{d}^{\prime}\end{array}$ & 0.265 & $\begin{array}{l}\text { d-axis transient open- } \\
\text { circuit time constant } T_{d 0}^{\prime}\end{array}$ & 8.62 \\
\hline $\begin{array}{l}\text { d-axis subtransient } \\
\text { reactance } x_{d}^{\prime \prime}\end{array}$ & 0.205 & $\begin{array}{l}\text { d-axis subtransient open } \\
\text { circuit time constant } T_{d 0}^{\prime \prime}\end{array}$ & 0.05 \\
\hline $\begin{array}{l}\text { q-axis synchronous } \\
\text { reactance } x_{q}\end{array}$ & 2.16 & $\begin{array}{l}\text { q-axis transient open- } \\
\text { circuit time constant } T_{q 0}^{\prime}\end{array}$ & 2.2 \\
\hline $\begin{array}{l}\text { q-axis transient } \\
\text { reactance } x_{q}^{\prime}\end{array}$ & 0.53 & $\begin{array}{l}\text { q-axis subtransient open- } \\
\text { circuit time constant } T_{q 0}^{\prime \prime}\end{array}$ & 0.07 \\
\hline $\begin{array}{l}\text { q-axis subtransient } \\
\text { reactance } x_{q}^{\prime \prime}\end{array}$ & 0.205 & $\begin{array}{l}\text { generator negative } \\
\text { sequence reactance }\end{array}$ & 0.205 \\
\hline
\end{tabular}

Appendix A2. The model and parameters of the regulator of $\mathrm{G}_{1}$

PSASP number 1 model of regulator, whose control block is shown as Fig. A1, is employed in the paper, parameters are as shown in Table A2. 


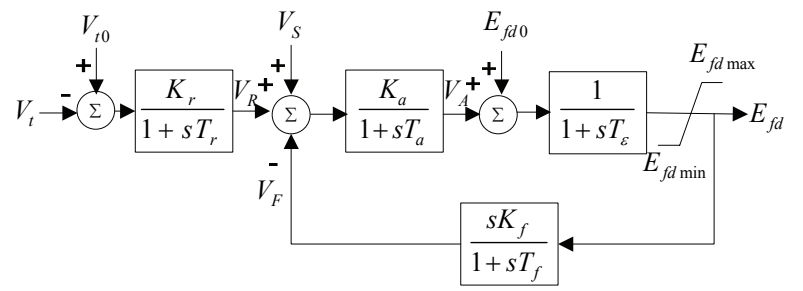

Fig.A1. Control block of PSASP number 1 model of regulator

Table A2. The parameter of the regulator of generator $\mathrm{G}_{1}$

\begin{tabular}{c|c|c|c}
\hline Variables & $\begin{array}{c}\text { Value } \\
\text { (pu or s) }\end{array}$ & Variables & $\begin{array}{c}\text { Value } \\
\text { (pu or s) }\end{array}$ \\
\hline$K_{r}$ & 1 & $T_{f}$ & 0.715 \\
\hline$T_{r}$ & 0.03 & $T_{e}$ & 0.01 \\
\hline$K_{a}$ & 300 & $E f d \max$ & 5 \\
\hline$T_{a}$ & 0.0001 & $E f d \min$ & 0 \\
\hline$K_{f}$ & 0.04 & & \\
\hline
\end{tabular}

Appendix A3. The model and parameters of the governor of $\mathrm{G}_{1}$

PSASP steam turbine governor model, whose control block is shown as Fig. A2, is employed in the paper, parameters are shown in Table A3.

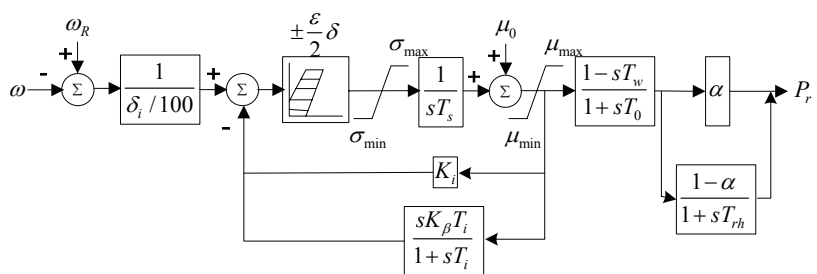

Fig. A2. Control block of PSASP steam turbine governor model

Table A3. The parameter of the governor of generator $\mathrm{G}_{1}$

\begin{tabular}{c|c|c|c}
\hline Variables & $\begin{array}{c}\text { Value } \\
\text { (pu or s) }\end{array}$ & Variables & $\begin{array}{c}\text { Value } \\
\text { (pu or s) }\end{array}$ \\
\hline$\delta_{i}$ & 5 & $\mu_{\max }$ & 1 \\
\hline$T_{s}$ & 0.5 & $\mu_{\min }$ & 0 \\
\hline$\varepsilon$ & 0.002 & $T 0$ & 0.2 \\
\hline$\sigma_{\max }$ & 1 & $\alpha$ & 1 \\
\hline$\sigma_{\min }$ & -1 & $T r h$ & 100000 \\
\hline$T_{w}$ & 0 & $K_{i}$ & 1 \\
\hline$K_{\beta}$ & 0 & $T_{i}$ & 100000 \\
\hline
\end{tabular}

Appendix A4 The Model and parameters of generator $\mathrm{G}_{2}$

Rated Capacity: 20000 MVA, Rated Voltage: 230KV.

Parameters (p.u) of $\mathrm{G}_{2}$ are the same with those of $\mathrm{G}_{1}$ with the rated capacity and rated voltage.
Appendix A5. Parameters of transformers

Table A4. The parameters of transformers

\begin{tabular}{c|c|c|c|c|c|c}
\hline $\begin{array}{c}\text { Trans- } \\
\text { former } \\
\text { Number }\end{array}$ & $\begin{array}{c}\mathrm{i} \text { side } \\
\text { Bus } \\
\text { name }\end{array}$ & $\begin{array}{c}\text { Reference } \\
\text { Voltage of } \mathrm{i} \\
\text { side bus }(\mathrm{kV})\end{array}$ & $\begin{array}{c}\mathrm{j} \text { side } \\
\text { Bus } \\
\text { name }\end{array}$ & $\begin{array}{c}\text { Reference } \\
\text { Voltage } \\
\text { of j side } \\
\text { bus(KV) }\end{array}$ & $\begin{array}{c}\text { Reactance } \\
x(\mathrm{pu})\end{array}$ & $\begin{array}{c}\text { Trans- } \\
\text { Former } \\
\text { Ratio } T_{k}\end{array}$ \\
\hline 9 & $\mathrm{G}_{1}$ & 18 & $\mathrm{~B} 1-500$ & 525 & 0.01 & 1.05 \\
\hline 10 & $\mathrm{G}_{2}$ & 230 & $\mathrm{~B} 3-500$ & 525 & 0.00467 & 0.95 \\
\hline
\end{tabular}

Appendix A6 Parameters of lines and compensation equipment

Table A5. The parameters of lines and compensation equipment

\begin{tabular}{c|c|c|c|c|c|c}
\hline $\begin{array}{c}\text { Line } \\
\text { Number }\end{array}$ & $\begin{array}{c}\text { i side } \\
\text { Bus } \\
\text { name }\end{array}$ & $\begin{array}{c}\text { j side } \\
\text { Bus } \\
\text { name }\end{array}$ & $\begin{array}{c}\text { Reference } \\
\text { Voltage of } \\
\text { Bus (KV) }\end{array}$ & $\begin{array}{c}\text { Resistance } \\
r(\mathrm{pu})\end{array}$ & $\begin{array}{c}\text { Reactance } \\
x(\mathrm{pu})\end{array}$ & $\begin{array}{c}\text { Earth } \\
\text { Capacity } \\
\frac{1}{2} B(\mathrm{pu})\end{array}$ \\
\hline 1 & $\mathrm{~B} 1-500$ & $\mathrm{~B} 2-500$ & 525 & 0.001885 & 0.015 & 0.544 \\
\hline 2 & $\mathrm{~B} 1-500$ & $\mathrm{~B} 2-500$ & 525 & 0.001885 & 0.015 & 0.544 \\
\hline 3 & $\mathrm{~B} 2-500$ & $\mathrm{~B} 3-500$ & 525 & 0.0037 & 0.0406 & 1.088 \\
\hline 4 & $\mathrm{~B} 2-500$ & $\mathrm{~B} 3-500$ & 525 & 0.0037 & 0.0406 & 1.088 \\
\hline 6 & $\mathrm{~B} 2-500$ & $\mathrm{~B} 3-500$ & 525 & 0 & 0.333 & 0 \\
\hline
\end{tabular}

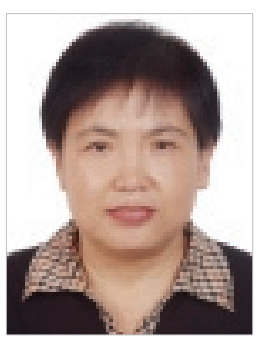

Wenying Liu She is the professor and PH.D Supervisor in North China Electric Power University. Her main research interests include power system analysis and control, power system dispatching, the security and defense of integrated power system.

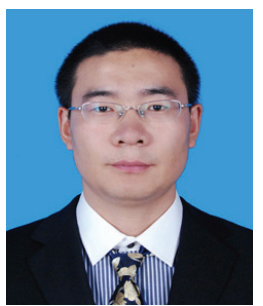

Rundong Ge He is the corresponding author. He started to pursue his M.D in North China Electric Power University in 2009, and then pursue his PH.D in 2011, both in Power System and Its Automation. $\mathrm{He}$ is currently a Ph.D candidate. His main research interests include power system smart dispat-ching, power system analysis and control.

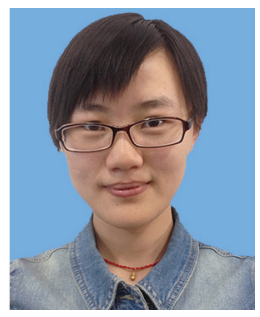

Dandan Zhu She received her B.S degree from North China Electric Power University, and is now pursuing her M.S degree in North China Electric Power University, both in Power System and Its Automation. Her main research interests include power system analysis and control, the security and defense of integrated power system. 


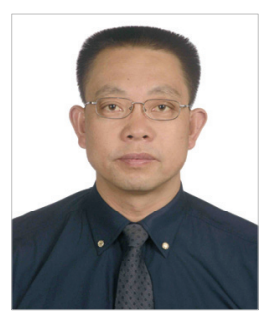

power system.

Weizhou Wang $\mathrm{He}$ is the advanced engineer in Gansu Electric Power Research Institute. He is experienced in operation, analysis and management of power system and the development of new technology and appliance. His recent researches are about reactive power, voltage and power loss in

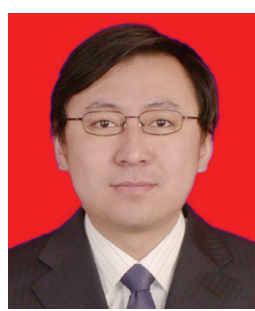

Wei Zheng $\mathrm{He}$ is the advanced engineer in Gansu Electric Power Research Institute. His researches are mainly about the stability calculation of power system, relay protection of power system.

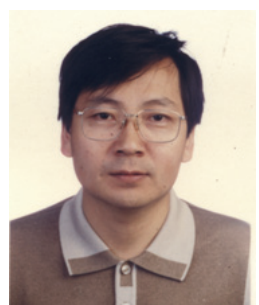

Fuzhou Liu $\mathrm{He}$ is the advanced engineer in Gansu Electric Power Research Institute. His researches are mainly about the operation of power system, energy saving in power system. 